DOI: $10.17805 / g g z .2017 .3 .6$

\title{
Социокультурная парадигма согласия как основа стратегии будущего
}

\author{
М. П. МЕНЯЕВА, В. С. НЕВЕЛЕВА \\ ЧЕЛЯБИНСКИЙ ИНСТИТУТ КУЛЬТУРЫ, Г. ЧЕЛЯБИНСК
}

В статье обосновывается необходимость и важность развития современного мира, общества и культуры в рамках социокультурной парадигмы согласия в связи с усилением противоречий на всех уровнях и во всех сферах человеческого бытия, конфликтным взаимодействием субъектов, т. е. господством отношений несогласия.

В силу возрастающего многообразия действующих сил и элементов в современной культуре и социальной жизни увеличивается число случайных взаимодействий, что способствует расширению зоны риска. Управление рисками возможно на основе социокультурной парадигмы согласия, разделяемого различными субъектами социокультурного взаимодействия представления о конструктивном потенциале принципа согласия в качестве основы нормотворчества, обеспечивающего эффективное выстраивание взаимоотношений в условиях возрастания различия интересов.

Осмысление социокультурной парадигмы согласия требует выявления ее философских оснований, анализа отношений согласия на всех уровнях человеческого бытия, а также раскрытия сути самого согласия.

Содержательные характеристики понятия «согласие», философско-культурологический смысл этого термина раскрыты через соотнесение с понятиями "гармония» и «единство», в которых зафиксированы различные аспекты объективного сосуществования различного. Рассмотрены соответствующие сути парадигмы согласия понятия "консенсус", “диалог», «компромисс», «ненасилие», закрепляющие сложившийся в истории культуры опыт практического взаимодействия социокультурных субъектов с разными интересами и целями.

Понятие «согласие» соотносится с противоположным ему по смыслу понятием «несогласие».

Социокультурная парадигма согласия рассматривается как образец мышления и понимания особенностей социокультурных отношений, в соответствии $c$ которым вырабатываются культурные формы и выстраиваются действия, направленные на обеспечение устойчивости, стабильности, безопасности человеческого существования (на индивидуальном и надындивидуальном уровнях), прежде всего, посредством конструктивного диалога, предполагающего компромиссы взаимовыгодного характера.

Объективная востребованность и безальтернативность социокультурной парадигмы согласия в ситуации усложнения социокультурных взаимодействий связана с согласием как социально значимой ценностью, как стратегической основой выживания всего человечества, обеспечивающей ему устойчивое и безопасное будущее.

Эффективность организации взаимоотношений в соответствии с социокультурной парадигмой согласия показана на примере разрешения Карибского кризиса (1962 г.) взрывоопасной обстановки, поставившей мир на грань третьей мировой войны ядерной, угрожавшей выживанию всего человечества.

Ключевые слова: социокультурная парадигма согласия; согласие; гармония; единство; консенсус; несогласие; Карибский кризис

\section{Sociocultural Paradigm of Consent as a Basis of the Strategy of the Future}

\author{
M. P. Menyaeva, V. S. Neveleva
}

CHELYABINSK INSTITUTE OF CULTURE, CHELYABINSK

The article proves the necessity and importance of the development of the modern world, society and culture within a sociocultural paradigm of consent in connection with strengthening of contradictions at all levels and in all spheres of human existence, conflict interaction of subjects, $i$. e. domination of the relations of disagreement. 
Due to the increasing variety of operating forces and elements in modern culture and social life the number of random interactions increases. This promotes the expansion of a zone of risk. Risk management is possible on the basis of the sociocultural paradigm of consent and the idea of the constructive potential of the principle of consent shared by various subjects of sociocultural interaction as the foundation of rulemaking providing an effective development of relationship in the conditions of increasing distinction of interests. Conceptualization of the sociocultural paradigm of consent demands a determination of its philosophical grounds, the analysis of the relations of consent at all levels of human existence, and also disclosure of the essence of consent.

Substantial characteristics of concept "consent" and the philosophical and culturological sense of this term are revealed through correlation with concepts "harmony" and "unity", which comprise various aspects of objective coexistence of the variety. The authors consider concepts "consensus", "dialogue", "compromise", "non-violence" that correspond to the essence of the paradigm of consent and consolidate the experience of practical interaction of sociocultural subjects with different interests and purposes which has been developed in the history of culture.

Concept "consent" is compared to concept "disagreement" that has an opposite meaning. The sociocultural paradigm of consent is considered as an example of thinking and understanding of the features of sociocultural relations according to which cultural forms are developed and actions aimed at ensuring sustainability, stability and the safety of human existence (at the individual and superindividual levels), first of all, by means of constructive dialogue assuming mutually advantageous compromises, are organized.

The objective relevance and lack of options for the sociocultural paradigm of consent in the situation of complicating sociocultural interactions is connected with consent as a socially important value and a strategic basis for the survival of all mankind providing its steady and safe future.

The efficiency of the arrangement of relationship according to the sociocultural paradigm of consent is shown by the example of the settlement of the Caribbean Crisis (1962) - an explosive situation in which the world was brought to the brink of the third world nuclear war threatening to the survival of all mankind.

Keywords: sociocultural paradigm of consent; consent; harmony; unity; consensus; disagreement; Caribbean Crisis

\section{BВЕАЕНИЕ}

Процессы, выражающие тенденцию глобализации в современном мире, вызывают своеобразное сопротивление, сопровождаются ее оборотной стороной - тенденцией к локализации. Это одна из причин для всякого рода конфликтов (этнических, национальных, религиозных и др.), в которых обнаруживается то, что связано с несогласием. Подчас наступательно агрессивный характер глобализации выражается в попытке навязать, всюду насаждать демократические, либеральные западные ценности. Эскалация такой глобализации происходит не с позиций парадигмы согласия, напротив, оборачивается эскалацией несогласия, проявляющегося в обострении конфликтов, принимающих ожесточенный характер. Подобные конфликты являются не только результатом сопротивления глобализационным процессам, но и того, что каждый пытается, обеспечивая (вплоть до абсолютизации) собственный свой интерес, не особо считаться с интересами других.

Несогласие порождает противоречия, которые влекут за собой нестабильность и напряженность, создают угрозы безопасности и устойчивости человеческого существования. Сегодня в ситуации мирового кризиса обостряются глобальные проблемы. От того, насколько ответственно будет дан ответ на эти вызовы, зависит будущее человечества. И если опыт преодоления кризисов существует, поскольку они уже неоднократно случались в истории и являются некой закономерностью, которую можно 
как-то контролировать, то глобальные проблемы - иное дело. Их главной причиной в самом общем виде является отношение человека к миру (внешнему и внутреннему), в котором преобладает установка на доминирование, порождающее несогласие. Среди глобальных проблем наиболее опасны угроза новой мировой войны, которая может быть спровоцирована активизацией международного терроризма (ядерного, биологического, информационного и т. А.), экологические проблемы, вызванные человеческой деятельностью, техногенными катастрофами. Решение общепланетарных проблем невозможно в одиночку, это «общее дело» для всех людей на планете, оно предполагает совместные заботу, интеллектуальные усилия и согласованные действия, объективной основой которых может быть общая для всех парадигма. Вызов человечеству в виде глобальных проблем и мирового кризиса требует ответа, суть которого заключается в установке на согласие и готовность действовать, исходя из него. В связи с этим можно вести речь о социокультурной парадигме согласия. Она имеет не только объективные основания в самой природе социальной жизни и культуры, но вводится и устанавливается сознательно, становится объективным основанием мышления и деятельности только тогда, когда принимается и разделяется членами общества как установка и готовность мыслить и действовать с точки зрения приоритета общечеловеческого, глобального, а не локального, национального, индивидуального, что, однако, не отменяет различия во взглядах, позициях, интересах и т. п., но способствует тому, чтобы различия не стали препятствием для ответственных решений.

Осмысление содержания социокультурной парадигмы согласия требует выявления ее философских оснований.

\section{ФИАОСОФСКИЕ ОСНОВАНИЯ \\ СОЦИОКУАБТУРНОЙ ПАРААИГМЫ СОГААСИЯ}

Аля прояснения сути и содержания социокультурной парадигмы согласия необходимо определиться с самим понятием согласия. Несмотря на то, что в разных областях теоретического научного познания, например, в политологии, социологии, конфликтологии ведется речь о согласии, исследование его на уровне частно-научного знания не позволяет выявить то предельное основание, без которого вряд ли возможно не только понимание сути феномена согласия, но и успех в достижении бесконфликтного существования на основе соответствующей социокультурной парадигмы. Выход к предельным основаниям предполагает философское осмысление, рефлексию философского уровня.

Определение понятия согласие дано в современной философской энциклопедии. Термин согласие трактуется как «специфическая форма взаимодействия предметов и процессов, отражающая стихийное и сознательное соединение противоположностей, их соотнесение Аруг с другом, достижение гармонии, симметрии и пропорциональности частей и целого в определенных соотношениях» (Новая философская энциклопедия, 2001: 589). На наш взгляд, для прояснения содержания и смысла согласия важно понять, что оно выводит на идею диалектической взаимосвязи противоположностей, взаимодействие, которых приводит к противоречию, а его разрешение происходит с образованием нового единства. Предложенное в энциклопедии расширительное толкование согласия, затрудняет его понимание применительно к социальной жизни или культуре, т. е. к миру человека, где все связано с присутствием субъективности, субъективных факторов, а, следовательно, предполагает наличие различного, многообразного, несходного, нетождественного. 
Понятие согласие употребляется и в более узком смысле. Оно означает «принятие противоположностями друг друга в тех или иных свойствах и взаимодействиях» (Новая философская энциклопедия, 2001: 589). Однако диалектическая идея о единстве противоположностей некоторого целого, фиксируя внимание на особенностях сосуществования противоположностей, не является достаточной для обозначения вариантов сосуществования различного во всем его многообразии, которое имеет место в социальном мире, где для сохранения устойчивости необходимо контролировать как различия внутренние, так и внешние по отношению к социальным образованиям, явлениям, процессам.

В самом общем смысле диалектику взаимосвязи, взаимодействия и взаимоотношений между противоположностями необходимо учитывать для осмысления особенностей согласия, но только как предельно общее основание для понимания отношений социокультурного характера. Согласие предполагает учет особенностей противоположных сторон, частей целого и то, что только их единство есть условие существования целого и его воспроизводства.

Согласие возможно только при наличии «голоса» у каждого, оно означает совмещение, сопряжение, соединение голосов и совсем не обязательно слияние их в один единственный голос. Суть согласия связана с моментом объективной совместности, т. е. существования вместе, одновременного существования различного, нетождественного друг другу. Согласие представляет собой форму взаимодействия различных сторон, предполагающую их единство, возможность бесконфликтного сосуществования. В ходе взаимодействия различных сторон происходит их взаимопроникновение, взаимопознание, за различиями обнаруживаются сходства, которые позволяют образовать единство органическое и целостность устойчивую. Наличие и акцентирование сходства настраивают на взаимопонимание противоборствующих, конфликтующих сторон, сглаживают противоречия, сближают полярности.

В сравнении с известным диалектическим единством противоположностей согласие предполагает единство как толерантное приятие друг друга, сосуществование любых различий, имеющих не только характер противоположностей. Аиалектическое единство отличается от согласия (Меняева, 2013b; 2014c), которое возникает как осознанное, осмысленное отношение друг к другу.

Применительно к социальной действительности отношения согласия предполагают сознательную организацию, и вряд ли могут быть стихийными. Стихийное соединение воспринимается как само собой разумеющееся, спонтанно возникающее, не требующее организации, сознательного устроения и установления, что не всегда имеет место в мире человеческих отношений, в социальной сфере, где термин согласие применяется для того, чтобы обозначить взаимодействие, отношения между разными социальными субъектами (личностями, этносами, народами и т. А.) на уровнях от индивидуального до надындивидуального, вплоть до глобального.

Поскольку согласие связано с сознательным стремлением к организации взаимодействий различного, о нем вряд ли возможно вести речь, применительно к природным объектам. По отношению к природному миру уместен термин гармония (греч. Harmonia - связь, созвучие, соразмерность, harmoso - приводить в порядок) в том его значении, когда он «в античной культуре служил для обозначения металлической скобы, соединяюеей различные детали единой конструкции» (Всемирная энциклопедия: Философия, 2001: 201-202). Гармония обеспечивается посредством точных пропорций, с помощью которых выражается мера. 
Согласие воспринимается нами как осознанное взаимодействие, направленное на поиск того сходного, что может объединять. Установление согласия требует работы человеческой мысли и специальных действий. Отсюда, согласие является культурно-опосредованной формой отношения. «На праксиологическом уровне согласие понимается как единомыслие, одинаковые с кем-либо мысли и чувства, намерения и убеждения; как духовное, психологическое состояние тех, кто не только соглашается на общее дело, но и принимает в его осуществлении практическое участие» (Новая философская энциклопедия, 2001: 589). Заметим, что единомыслие следует понимать не только как одинаковые мысли, но, скорее, как движение мыслей в одну сторону. Единство, в котором все унифицируется, становится неразличимым, всеобщим, является тотальным единством. В гармоническом единстве «различия сохраняются и согласуются друг с другом, порождая единство в многообразии» (Меняева, 2014f: 104).

Можно вести речь о вариантах согласия, выделяемых по разным основаниям. «Вопервых, различают согласие-намерение, согласие-волеизъявление, а также согласиедействие с его результатом. Во-вторых, согласие подразделяется на событийное и процессуальное; первое возникает и достигается в конкретной, дискретной ситуации, а второе характеризуется длительностью и протяженностью во времени, разделенностью на разные этапы, соединенные между собой и поэтому выступающие как звенья в общей цепи процессов соединения противоположностей» (Новая философская энциклопедия, 2001: 589). Аействительно, если исходить из того, что достижение согласия в человеческом мире предполагает согласование, то следует отличать процесс согласования от складывающихся в ходе него отношений согласия как его результат.

Согласие как отношение между различными субъектами «основывается на презумпции доверия, равнозначности, равноценности другой стороны, трактуемой не в качестве объекта, а в качестве наделенного автономным статусом субъекта. Субъект-объектному принципу принуждения и насилия философия согласия противопоставляет субъект-субъектный, диалоговый принцип» (Новая философская энциклопедия, 2001: 589). Однако равнозначность и равноценность взаимодействующих сторон - это, все же, идеальный случай. Стороны могут иметь разный статус и иногда согласие между ними - просто вынужденная мера, которая отражает не равнозначность или равноправие сторон, а просто компромисс. Поэтому помимо диалогового принципа необходим и принцип ненасилия как руководство к действию не путем подавления, подчинения, манипуляции, а путем уступок.

«Согласие продуктивнее понимать не как априорно заданное единодушие, а как процедуру взаимного открытия сторонами все новых и новых смыслов кооперации и сотрудничества, совместного ответа на внешние вызовы» (Новая философская энциклопедия, 2001: 589). Аобавим, что согласие требует не только совместной ответственности, но и ответственности каждого субъекта ( Меняева, 2013е: 422-424).

Итак, понятие согласие имеет специфику. На наш взгляд, она состоит в том, что оно применимо, прежде всего, к социокультурной сфере, имеет в качестве объективного основания необходимую совместность существования различных субъектов. Принцип согласия не может быть отождествлен с диалектическим принципом единства противоположностей, поскольку предполагает сознательное установление способа взаимодействия различного и отношений между различными элементами социального целого. Последнее предполагает приоритет общего и целого, который становит- 
ся особенно важным тогда, когда то, что стоит на стороне различий, начинает обозначаться явно и наступательно, поскольку доминирование особенностей способствует их обособлению, вследствие чего общность оказывается невозможной.

Согласие возникает из общих усилий. Общее не дано в готовом виде и предполагает поиск, оно создается, делается вместе, в нем разное совпадает, момент сходства есть момент равенства всех. Общее не поглощает, а обнимает все различия и выводит к границе нового качества взаимодействия с точки зрения приоритета мирного сосуществования.

Близким по смыслу термину согласие является термин консенсус (от лат. consensus - согласие, единодушие), который трактуется как «ориентированная на сохранение существующих систем отношений парадигма взаимодействия, связанная с намерением партнеров достичь общности определения ситуации на основе взаимопонимания, без напряженности в отношениях» (Хоруженко, 1997: 213). Поскольку термин консенсус чаще всего используется в политологии, имеет смысл считать его элементом политологического дискурса. Однако этот термин может применяться вообще к тому, что связано с отношениями партнерства - экономического, политического, торгового, даже научного. Партнерство всегда предполагает сотрудничество, т. е. программу совместных действий для решения конкретных задач. Консенсус представляет собой способ договориться по обсуждаемым вопросам, чтобы действовать, сотрудничать. В отличие от термина консенсус термин согласие применяется по отношению к разным сферам бытия (экономической, политической, культурной и т. А.) и его уровням - социальному и индивидуальному.

«Согласие более пластично. Можно вести речь о полном или частичном согласии. Полное согласие не всегда достижимо даже при обоюдном желании, поскольку комуто приходится совсем отказаться от своих интересов. Полное согласие может иметь своим основанием конформизм или безразличие, которое порождает безответственность. Поэтому такое согласие является мнимым. Подлинное согласие основано на свободном волеизъявлении, требует доброй воли к пониманию, предполагает отношения на равных, при которых не отбрасываются различия, а преодолевается их расчленение и утверждается взаимная близость» (Меняева, 2009d: 127).

Согласие не следует отождествлять с соглашательством. В толковом словаре соглашательство трактуется как «политика и поведение соглашателя» (Ожегов, 1994: 731). «Соглашатель - 1) беспринципный политик, идущий на уступки, компромиссы своим противникам; 2) человек, склонный к компромиссам, приспособленец (Ожегов, 1994: 731). Приспособленец, конформист бездумно следует общим мнениям, тенденциям (Ожегов, 1994: 287). При соглашательстве происходит подчинение одного другому, тем самым различия остаются и отношение между различными сторонами становятся напряженными.

Человек согласный руководствуется принципом разумного компромисса, проявляет соучастие, сопереживает и не противопоставляет себя другим, наоборот, он солидарен, поэтому становится другом, единомышленником, собеседником, союзником, партнером, компаньоном, соратником, соучастником и т. п. В противоположность ему человек несогласный - неуступчивый, вступает в оппозицию, которая не всегда представляет угрозу, но вызывает настороженное отношение.

Человек несогласный характеризуется по-разному. С одной стороны, - как вздорный, сварливый, идущий поперек, неуступчивый, что может быть особенностью его психологического склада. С другой - как человек, который имеет свою собствен- 
ную позицию, точку зрения и готов отстаивать их, спорить (известно, бытующее мнение, что в споре рождается истина). Подобное несогласие может порождать конфликт, противостояние, борьбу. Человек несогласный с господствующей идеологией, властью, режимом и т. А. вступает в оппозицию, поэтому может быть подвергнут наказаниям, преследованиям, репрессиям, гонениям. В тоталитарной системе человек несогласный воспринимается как диссидент, противник, враг. Однако человек инакомыслящий необходим для существования либерального общества. Человек инакомыслящий, иноверец иногда вызывает настороженное отношение к себе со стороны окружающих, несмотря на то, что его несогласие не всегда представляет угрозу для них.

Слово «несогласие» отличается от слова «согласие» приставкой «не»,тождественной слову «нет». Последнее может означать с одной стороны, отрицание согласия словом и делом, противостоять ему, с другой - отказ как воздержание, ограничение, что может иметь позитивное значение.

Если согласие предполагает, что различное необходимо сосуществует в целостности, то несогласие акцентирует существование различий самих по себе, что обозначает не всегда замкнутость, самодостаточность, а характеризует их неприятие по отношению друг к другу, поэтому образование целостности невозможно.

Сосуществование разных социальных субъектов может быть мирным, терпимым Аруг к другу или конфликтным, враждебным. Бесконфликтное сосуществование является взаимно необходимым для сохранения целостности мира во всем его многообразиии его воспроизводства. Согласие возникает из осознания людьми, группами, организациями, государствами различий в позициях, интересах, целях и проявляется в общности, совпадении, тождестве интересов, ценностей, смыслов. Оно влечет за собой взаимотерпимость различных противостоящих сторон и достигается путем нахождения между ними компромиссов, суть которых состоит в защите собственных интересов ценой взаимных уступок.

Взаимное и добровольное согласие ведет к солидарности, сотрудничеству, кооперации и консолидации как механизмам интеграции. Обоюдное стремление к согласию в человеческом мире способствует формированию единства и целостности, которые имеют характер не тотальный, не механический, а органический и гармонический, что является залогом стабильного и устойчивого развития.

Если в теории существуют понятия, которые больше соответствуют «чистому» представлению о согласии, идеальному образцу - гармонии, например, то в практике взаимодействия социокультурных субъектов с разными позициями, интересами, целями и т. А. выработаны соответствующие этому образцу типы отношения согласия в разных сферах общественной жизни. «В экономической сфере отношения согласия проявляются в сотрудничестве, партнерстве, кооперации, в социальной сфере - в солидарности, взаимопомощи, взаимоподдержке, в сфере межличностных отношений - в доверии, дружбе, любви. Согласие в военно-политической сфере предполагает образование разного рода объединений - союз, коалиция, блок и т. А., возникающих для достижения общих целей, например, для борьбы против общего врага.

Отношения согласия, проявляющиеся в солидарности, взаимопомощи, взаимоподдержке, братстве между людьми, обеспечивают им выживание. Сотрудничество, партнерство, кооперация исключают механическую связь. Преобразования, совершенные совместными усилиями, т. е. без применения по отношению друг к другу насилия, более эффективны. Они позволяют достичь гармонического единства и оптимального порядка в человеческом мире. 
Скрепляя различные стороны в совместном существовании, необходимом для выживания и созидания, отношения согласия базируются на ценностях ненасилия, справедливости, милосердия, толерантности и т. А. и необходимы на всех уровнях человеческого бытия (индивидуальном, надындивидуальном, глобальном). Их значимость заключается в обеспечении стабильности и безопасности человеческого существования, сохранении целостности мира во всем его многообразии, тем самым устойчивого развития.

Напротив, «отношения несогласия, выражающие взаимное неприятие сторон, становятся источником не просто существования порознь, а противопоставления, борьбы, конфликтов (вплоть до военных)» (Меняева, 2015а: 17). Тем самым они разрушают единство человеческого бытия на всех его уровнях (от индивидуального до глобального). Взаимное неприятие сторон выражается в недоверии, ненависти, вражде по отношению друг к другу, в восприятии другого как чужого и чуждого. Подобные отношения предполагают недоброжелательность, неуважение, соперничество и конкуренцию. Противоречия составляют суть различных отношений несогласия, от отдельных проявлений нетерпимости до войн. Акцент на различия не способствует сближению, неравенство дает повод давлению, насилию, господству одного над другим, его уничтожение. Взаимное неприятие исключает взаимные уступки, порождает борьбу, конфликты, конфронтации и войны между людьми, нациями, странами и цивилизациями, которые ведут к гибели.

В мире человеческих отношений согласие является важным в условиях борьбы, конфликтов, противоречий. Именно в этих условиях возможно появление «идеи согласия, которая ориентирована на разрешение противоречий и выступает средством их преодоления. Идея согласия позволяет сказать, что согласие выделяется как форма отношения, без которой невозможно образование общества и бесконфликтного существования в нем.

Аля социальной жизни необходим принцип согласия, без него невозможно общежитие, мирное сосуществование. Принцип согласия есть руководство действовать согласованно, вместе, сообща, что предполагает доверительные отношения, характеризующиеся взаимопониманием, взаимной доброжелательностью и даже дружбой» (Меняева, 2015а: 22-23).

Путь достижения согласия в человеческом мире, в личной и общественной жизни проблематичен. Однако без согласия не обойтись, так как оно выступает в качестве адаптирующего механизма к общественной сфере, внешнему миру. В древности социальное согласие составило основу групповой солидарности и консолидации, необходимых для выживания людей в сложных условиях окружающей среды. Социальнополитическое и гражданское согласие обеспечило развитие и процветание государственной системы в Аревней Греции и Аревнем Риме. В средневековой Европе согласие в вере в Иисуса Христа стало основанием для возникновения христианской религии как мировой, объединившей людей из разных этносов и слоев общества, способствовало развитию христианской культуры, объединившей европейский мир.

Поиск гражданско-правового согласия в эпоху Нового времени стимулировал развитие научного знания, образования и просвещения. Согласие в правовой сфере означало установление единства между гражданами, которое стало основой сотрудничества и партнерства, необходимых для прогресса в общественной жизни.

Индустриальный этап в развитии общества и цивилизации стимулировал переосмысление путей и средств достижения согласия в связи с духовным кризисом, возник- 
шим в результате процесса технизации. Необходимость выйти из кризиса и обеспечить устойчивость в развитии усилила потребность в гармонии. Идеал гармонии был рожден в Античности и возрожден гуманистами в последующие века. Возникшие в Новое время противоречия в отношениях человека с природой породили проблему экологического согласия, которая остается актуальной и по сей день.

Установление отношений согласия предполагает диалог, который обладает потенциалом объединения на уровне полярных точек зрения, представляет собой процесс взаимного сближения, допускающий при этом определенную степень расхождения. Аиалог предполагает движение навстречу друг к другу с целью быть услышанными, понятыми, принятыми при условии готовности изменяться самому. Понимание друг друга невозможно без выработки общих понятий, содержащих общие смыслы. Согласие по смысложизненным позициям позволяет сделать противоречия управляемыми.

Аиалог - это смысловое взаимодействие, в ходе которого возможен выход к общему, совместно разделяемому ответу, согласование интересов, целей, ценностей, оказание взаимного доверия, совершение взаимных уступок, утверждение взаимных обязанностей, правил, норм и их закрепление, в том числе в соглашениях различного содержания и уровня. Аля достижения согласия требуются взаимные усилия, добрая воля, взаимотерпимость, а также возможно применение технологий (к ним относятся проведение круглых столов, конференций, форумов и т. п.), способствующих поиску общего. Важную роль при этом играют институциональные формы, которые представляют собой объединения, регулирующие, упорядочивающие, контролирующие выполнение установленных обязанностей, правил и норм, закрепленных в документальных формах - договорах, соглашениях, контрактах и т. А.

Выработка различных культурных форм, в том числе нормативного характера, организация конструктивных межсубъектных взаимоотношений невозможна без общей установки на согласие. Эта установка предполагает общность представлений о принципиальных основаниях, обеспечивающих возможность мирного сосуществования различных социальных субъектов с учетом их частных интересов и готовности исходить из интересов совместного бесконфликтного сосуществования как основы движения в будущее. Подобная установка может быть только результатом совместных сознательных усилий социальных субъектов (в этом смысле она приобретает характеристику объективности), обозначая парадигмальные границы выстраивания, организации реальных отношений, способов взаимодействия социальных субъектов. В этом смысле согласие может быть представлено как социокультурная парадигма, как онтологическое основание нормотворчества. В данном случае мы разделяем точку зрения А. В. Павлова о том, что парадигма имеет не только гносеологическое, но и онтологическое толкование как "реальное основание любой социальной системы» (Павлов, 2010: 61).

Будучи принятой, социокультурная парадигма согласия становится онтологическим основанием организации социального бытия на всех уровнях.

\section{СОЦИОКУАЬТУРНАЯ ПАРАДИГМА СОГААСИЯ КАК ЭТААОН МЫШАЕНИЯ И ПРАКТИЧЕСКОГО АЕЙСТВИЯ: КАРИБСКИЙ КРИЗИС}

Примером проявления социокультурной парадигмы согласия в XX в. стала ситуация Карибского кризиса.

Карибский кризис (1962 г.) был порождением «холодной войны», в ходе которой две сверхдержавы (СССР и США) боролись за контроль над развитием политических 
процессов в мире. Кризис был вызван прежде всего стремлением этих стран достичь превосходства в сфере политического влияния, в военной силе, которое оформилось в осознанное противостояние между двумя обладательницами ядерного оружия. В момент Карибского кризиса конфронтация между США и СССР достигла такого предела, который представлял собой угрозу Третьей мировой войны - ядерной, способной уничтожить не только конфликтующие стороны, но и все человечество (омницид).

Карибский кризис стал кульминацией, «горячей» точкой «холодной войны», наглядно показав политическим элитам обеих сверхдержав, что балансирование на грани войны может привести к непоправимым для них последствиям. Ответственность за эти последствия «несли обе стороны, как американская, нагнетавшая горячую атмосферу вокруг Кубы, так и советская, спровоцированная антикубинской кампанией на посылку ракет за океан» (Косов. Электронный ресурс).

Осознание того, насколько близко мир подошел к войне, осознание катастрофических последствий для всего человечества, к которым мог привести Карибский кризис, заставило обе сверхдержавы по-новому взглянуть на доктрину ядерного устрашения и пойти на диалог их руководителям - Н. С. Хрущеву и Аж. Кеннеди. В ходе него они отказались от военного пути разрешения конфликта и, оказав доверие друг к другу, совершили взаимные уступки, что позволило им договориться и найти общее решение, принять совместные, согласованные меры, налагающие на обе страны и их лидеров ответственность за сохранение мира для всего человечества, имеющей значимость, ценность для всей планеты. Закрепление этого решения было осуществлено при посредстве Организации Объединенных Наций в тексте Аоговора о запрещении ядерных испытаний в трех сферах - водной, воздушной и земной (1963 г.), а также ряда договоров, которые позволили начать осуществлять сотрудничество и партнерство между двумя сверхдержавами.

Событие Карибского кризиса прямо обнаружило недееспособность сложившихся образцов, культурных форм разрешения конфликтов, нежизнеспособность ценностей господства одной воли, неприятия другого, иного, действия с позиций одной силы, бескомпромиссность.

Именно с ситуации Карибского кризиса отдельные проявления воли к согласию, которые ситуативно возникали в истории человечества и ранее, перешли в новое качество - осознанную необходимость и безальтернативность выхода к согласию в условиях конфликтного существования.

Аействия советского руководителя Н. С. Хрущева и американского президента Аж. Кеннеди свидетельствует о последовательном движении руководителей двух стран от отношений несогласия к отношениям согласия. Установлению последних способствовало принятие друг от друга предложений об отказе от военного пути разрешения конфликта и поиск компромиссов. Направление поступательного движения определялось стремлением мирными средствами разрешить конфликт, не допустить ядерной войны и сохранить мир. Именно оно стало основой для взаимодоверия и взаимопонимания.

Будучи противниками, Н. С. Хрущев и Аж. Кеннеди отказались от противостояния, проявив в отношениях друг с другом сдержанность, взаимоуважение и взаимодоверие. Они вступили в переговоры и согласовали свои различия в национальных интересах на основе общей идеи - недопустимости войны, проявив заботу о сохранении мира. В результате они стали союзниками. Исходя из осознания ответственности пе- 
ред всем человечеством, оба проявили благоразумие и политическую мудрость. Между ними сложились отношения согласия, опыт которых зафиксирован в воспоминаниях официальных лиц и близких людей.

Аействия, которые предпринимали лидеры двух сверхдержав, способствовали успешному разрешению кризиса, поскольку были обдуманными, исключали импульсивность и произвол. Обе стороны достигли взаимоприемлемого пути разрешения конфликта, выполнили свои обязательства. Выход из кризиса осуществлялся в соответствии с принципами международного права и ненасилия, которые не привели к нарушению мира.

С события Карибского кризиса «установка на поиск согласия вошла в практику межгосударственных отношений и закрепилась в ней через совокупность определенных инструментов, средств, технологий» (Меняева, 2015а: 32).

Карибский кризис принято считать примером «разумного разрешения» острого политического конфликта дипломатическими методами, а не военными. «В период крайней напряженности, политическая воля к ведению активного диалога, выдержка, способность услышать другую сторону и пойти на реальный компромисс все это не давало “холодной войне" перерасти в ядерную» (Савойский. Электронный ресурс).

Отойти от края пропасти позволили личные контакты Н. С. Хрущева и Аж. Кеннеди, которые в момент критической ситуации вышли на новый уровень идентичности. Они стали воспринимать друг друга не в качестве врагов, а как равно способных принимать решения в интересах всего человечества.

Руководителям двух стран удалось разрешить конфликт ненасильственным путем и закрепить достигнутые результаты договором всемирного значения, налагающим запрет на испытание ядерного оружия, мощь которого позволяет в один момент уничтожить все человечество.

Карибский кризис не привел человечество к гибели, а вывел две сверхдержавы к отношениям взаимного доверия, предотвратив опасность мировой войны и обеспечив условия для мирного сосуществования и развития человечества. Главным итогом Кубинского кризиса, наряду с предотвращением термоядерной войны, явилось укрепление чувства ответственности у обеих сторон.

Огромное значение для мирного разрешения Карибского кризиса имели личные качества американского и советского лидеров. При всей своей разности они оказались способными не поддаться эмоциям, проявить политическую волю и выйти на такие решения, которые отвечали главным целям каждой из сторон (для СССР - ограждение Кубы от угрозы вторжения, а для США - устранение ракет с Кубы) и единой цели - не допустить перерастания кризиса в термоядерную дуэль. Естественно, подобный исход кризиса нельзя считать гарантированным во всех случаях.

\section{ЗАКАЮЧЕНИЕ}

Таким образом, социокультурная парадигма согласия как установка на мирное сосуществование, как образец бесконфликтного взаимодействия, основанного на диалоге, предполагающем поиск компромиссов взаимовыгодного и конструктивного характера, а также волю к пониманию друг друга крайне важна для сохранения единства разнообразия мира, его безопасности, созидательного и устойчивого развития в будущем. 
Будущее всегда является неопределенным, так как представляет собой сферу возможного, но будущее необходимо сопряжено идеальными представлениями, в нем идеалы, образцы того, на каких скрепах мир мог бы существовать устойчиво, бесконфликтно, имея при этом перспективы в развитии.

Социокультурная парадигма согласия обретает особое значение в ситуации нынешнего мирового кризиса, в условиях усиления глобальных проблем, так как означает способность мыслить и действовать не только с позиции национальных интересов, эгоистичных, своекорыстных целей, частных, локальных рамок, но соотносить их с глобальным масштабом, с рамками мира в целом, всего человечества, руководствуясь приоритетом его интересов.

Социокультурная парадигма согласия предполагает понятие согласия, идею согласия и принцип согласия, который, будучи обозначен на теоретическом уровне, может стать принципом практического действия, а также эталон согласия в качестве образца и онтологического основания для решения задач, связанных с преодолением разногласий, конфликтов, противоречий, которые сопровождают развитие общества и культуры, начиная с древности.

Согласие является важным и ценным, так как оно жизнеутверждающе, оно обеспечивает мирное сосуществование социальных субъектов во всем их многообразии, сохранение жизни для всех и каждого на планете Земля.

Употребляемое в философии понятие согласие сопряжено с такими понятиями, как единство и гармония. Гармония несет в себе характеристику соотношения различных частей и предполагает такую связь различного, которая скрепляет отдельное на основе обнаружения меры разрозненности. Единство предполагает наличие множества, их связь друг с другом, при которой различия могут сохраняться (гармоническое единство) или устраняться, становиться неразличимыми (тотальное, всеобщее единство). Согласие означает совмещение, соединение, сближение различий, искдючая как их слияние, так и сведение к противоположностям, вступающим в противоречие друг с другом. Различия удерживаются вместе на основе их равной значимости, что позволяет достичь единства многообразия. Согласие устанавливается путем поиска общего, (тождественного) между разными сторонами в ходе диалога, при движении навстречу друг другу и осуществлении разумных, взаимных уступок на основе доброй воли к пониманию друг друга. Согласие выражает паритет, позволяет держаться на равныхпо отношению к установленному общему.

Понятие согласие сопряжено с понятием консенсус, поскольку организуется сознательно, является результатом процесса согласования и предполагает готовность взаимодействовать без применения насилия, регулировать противоречивые ситуации в диалоговой форме. Однако в отличие от понятия консенсус понятие согласие шире по своему содержанию, так как применимо ко всем сферам человеческого бытия.

Онтологической основой для согласия служит родовое начало в человеческой природе. По своей природе согласие социально. Согласие утверждается не путем отрицания несогласия, а через его сдерживание, обуздание, приведение в границы меры, что требует понимания и воли и позволяет выйти на компромисс, который сохраняет момент несогласия сторон, но только в несущественном.

Парадигма согласия пока не является тем образцом мышления и практического действия, который всегда и всеми принимается во внимание. Но периодически она проявляется с очевидностью. Наиболее отчетливо жизнеспособность парадигмальной установки согласия проявилась в ситуации Карибского кризиса, когда мир ока- 
зался на грани уничтожения. Именно в ситуации крайней опасности, по всей вероятности, впервые на международном уровне проявилась воля к согласию, конструктивная сила и роль согласия. В ходе кризиса было найдено взаимоприемлемое и ответственное политическое решение, которое стало возможностью сохранения мира для всего человечества. Взаимные действия Н. С. Хрущева и Аж. Кеннеди представляют собой опыт отношений согласия на глобальном уровне, который включает в себя также индивидуальный, личностный уровень.

Именно с точки зрения социокультурной парадигмы согласия обнаруживается то, насколько велика роль лидеров государств, и как резко возрастает их ответственность за принимаемые решения в современном мире, который представляет собой сплошную зону риска в эпоху наличия ядерного оружия, в связи с чем человечество вновь оказывается перед выбором: быть или не быть?

\section{СПИСОК АИТЕРАТУРЫ}

Всемирная энциклопедия: Философия (2001) / ред. А. А. Грицанов. М. : АСТ, Мн. : Харвест, Современный литератор. 1312 с.

Косов, А. П. Место Карибского Кризиса 1962 г. в советско-американских отношениях (по материалам российской историографии) [Электронный ресурc] URL: http://www.hist.bsu.by/ nauka/konferentsii/187-2011-02-17-11-33-07/materialy-konferentsij/xxi-vek/581-mesto-karibskogo-krizisa-1962-g-v-sovetsko-amerikanskikh-otnosheniyakh-po-materialam-rossijskoj-istoriografii.html (дата обращения: 05.08.14).

Меняева, М. П. (2015а) Культура согласия: сущность, становление, воспроизводство: автореферат дис. ... А-ра филос. наук / М. П. Меняева; Челябинск. 41 с. URL: http://dlib.rsl.ru/ 01006645164 (дата обращения: 25.04.2017).

Меняева, М. П. (2013b) Идея согласия в контексте учения о всеединстве В. С. Соловьева // Вестник славянских культур. № 4 (т. 30). С. 5-10.

Меняева, М. П. (2014c) Культура согласия - стабилизационный и инновационный потенциал современной культуры // Ценности и смыслы. № 5 (33). С. 125-133.

Меняева, М. П. (2009d) Иогико-семантический и философско-культурологический анализ понятия «культура согласия»// Вестник Челябинского государственного университета. Серия Философия. Социология. Культурология. № 33 (171). С. 126-130.

Меняева, М. П. (2013е) Принцип согласия в контексте концепции ноосферы В. И. Вернадского // Мир науки, культуры, образования. №5 (42). - С. 422-424.

Меняева, М. П. (2014f) Принцип согласия в философии «общего дела» Н. Ф. Федорова // Знание. Понимание. Умение. № 3. С. 102-107.

Новая философская энциклопедия : в 4 т. (2001) / Ин-т филос. РАН; Нац. общ.-науч. фонд; науч.-ред. сов.: В. С. Степин, А. А. Гусейнов, Г. Ю. Семигин и др. М. : Мысль. Т. 3. С. 589.

Ожегов, С. И. (1994) Толковый словарь русского языка: 80000 слов и фразеологических выражений / С. И. Ожегов, Н. Ю. Шведова. Российская АН.; Российский фонд культуры; М. : АЗЪ. 928 c.

Павлов, А. В. (2010) Аогика методология науки: Современное гуманитарное познание и его перспективы: учеб пособие. М. : Флинта: Наука. 344 с.

Савойский, А. Г. СССР - США Ультиматум Кеннеди Хрущеву или военная дипломатия Кубинского кризиса // [Электронный ресурс] URL: http://nasledie.ru/?q=node/1642 (дата обращения: 03.07.14).

Хоруженко, К. М. (1997) Культурология. Энциклопедический словарь. Ростов-на-Аону: Изд-во «Феникс». 640 с.

Vsemirnaia entsiklopediia: Filosofiia [World encyclopedia: Philosophy] (2001) / red. A. A. Gritsanov. Moscow, AST, Minsk, Kharvest, Sovremennyi literator. 1312 p. (In Russ.). 
Kosov, A. P. Mesto Karibskogo Krizisa 1962 g. v sovetsko-amerikanskikb otnosheniiakb (po materialam rossiiskoi istoriografii) [ The place of the Caribbean Crisis of 1962 in the SovietAmerican relations (on materials of the Russian historiography)] [online] Avaible at: http://www.hist.bsu.by/nauka/konferentsii/187-2011-02-17-11-33-07/materialy-konferentsij/xxivek/581-mesto-karibskogo-krizisa-1962-g-v-sovetsko-amerikanskikh-otnosheniyakh-po-materialam-rossijskoj-istoriografii.html (access date: 05.08.14). (In Russ.).

Meniaeva, M. P. (2015a) Kul'tura soglasiia: sushchnost', stanovlenie, vosproizvodstvo [Culture of a consent: essence, formation, reproduction]: abstract of the diss. ... Doctor of Psychology. Cheliabinsk. 41 p. [online] Avaible at: http://dlib.rsl.ru/01006645164 (access date: 25.04.2017). (In Russ.).

Meniaeva, M. P. (2013b) Ideia soglasiia v kontekste ucheniia o vseedinstve V. S. Solov'eva [The idea of a consent in the context of the doctrine on V. S. Solovyov's vseedinstvo]. Vestnik slavianskikb kul'tur. No. 4 (t. 30). Pp. 5-10. (In Russ.).

Meniaeva, M. P. (2014c) Kul'tura soglasiia - stabilizatsionnyi i innovatsionnyi potentsial sovremennoi kul'tury [Culture of a consent - the stabilization and innovative potential of modern culture]. Tsennosti i smysly. No. (33). Pp. 125-133. (In Russ.).

Meniaeva, M. P. (2009d) Logiko-semanticheskii i filosofsko-kul'turologicheskii analiz poniatiia «kul'tura soglasiia» [Logiko-semantichesky and philosophical and culturological analysis of the concept «culture of a consent»]. Vestnik Cheliabinskogo gosudarstvennogo universiteta. Seriia Filosofiia. Sotsiologiia. Kul'turologiia. No. 33 (171). Pp. 126-130. (In Russ.).

Meniaeva, M. P. (2013e) Printsip soglasiia v kontekste kontseptsii noosfery V. I. Vernadskogo [The principle of a consent in the context of the concept of a noosphere of V. I. Vernadsky]. Mir nauki, kul'tury, obrazovaniia. No. 5 (42). Pp. 422-424. (In Russ.).

Meniaeva, M. P. (2014f) Printsip soglasiia v filosofii «obshchego dela» N. F. Fedorova [The principle of a consent in philosophy of «common cause» of N. F. Fedorov]. Znanie. Ponimanie. Umenie. No. 3. Pp. 102-107. (In Russ.).

Novaia filosofskaia entsiklopediia [New philosophical encyclopedia] V 4-kh t. (2001) / In-t filos. RAN; Nats. Obshch.-nauch. Fond; Nauch.-red. Sov.: V. S. Stepin, A. A. Guseinov, G. Iu. Semigin i dr. Moscow, Mysl'. Vol. 3. P. 589. (In Russ.).

Ozhegov, S. I. (1994) Tolkovyi slovar' russkogo iazyka: 80000 slov $i$ frazeologicheskikb vyrazhenii [Explanatory dictionary of Russian: 80000 words and phraseological expressions] Rossiiskaia AN.; Rossiiskii fond kul'tury; Moscow, AZ»». 928 p. (In Russ.).

Pavlov, A. V. (2010) Logika metodologiia nauki: Sovremennoe gumanitarnoe poznanie i ego perspektivy [Logic science methodology: Modern humanitarian knowledge and its prospects]: ucheb. posobie. Moscow, Flinta : Nauka. 344 p. (In Russ.).

Savoiskii, A. G. SSSR - SShA Ul'timatum Kennedi Khrushchevu ili voennaia diplomatiia Kubinskogo krizisa [The USSR - the USA the Ultimatum to Kennedy Khrushchev or military diplomacy of the Cuban crisis] [online] Avaible at: http://nasledie.ru/?q=node/1642 (access date: 03.07.14). (In Russ.).

Khoruzhenko, K. M. (1997) Kul'turologiia. Entsiklopedicheskii slovar'. [Cultural science. Encyclopedic dictionary.] Rostov-na-Donu, Feniks. 640 p. (In Russ.).

Аата поступления: 10.05.2017 2.

Меняева Марина Петровна - доктор философских наук, доцент кафедры философских наук Челябинского государственного института культуры. Адрес: 454091 Россия, г. Челябинск, ул. Орджоникидзе, д. 36 а. Тел.: 8(351)263-89-73. Эл. адрес: kaf-fil@chgaki.ru

Невелева Вера Сергеевна - доктор философских наук, профессор, зав. кафедрой философских наук Челябинского государственного института культуры. Адрес: 454091 Россия, Челябинск, ул. Орджоникидзе, А. 36 а. Тел.: 8(351)263-89-73. Эл. адрес: kaf-fil@chgaki.ru 
Menyaeva Marina Petrovna, Doctor of Philosophy, Associate professor, Deparment of Philosophical Sciences, Chelyabinsk State Institute of Culture. Postal address: 36 Ordzhonikidze St., Chelyabinsk, Russian Federation, 454091. Tel./ fax: 8 (351) 263-89-73. E-mail: kaf-fil@chgaki.ru

Neveleva Vera Sergeyevna, Doctor of Philosophy, Professor, Chair, Department of Philosophical Sciences, Chelyabinsk State Institute of Culture. Postal address: 36 Ordzhonikidze St., Chelyabinsk, Russian Federation, 454091. Tel./fax: 8 (351) 263-89-73. E-mail: kaf-fil@chgaki.ru

Аля читирования:

Меняева М. П., Невелева В. С. Социокультурная парадигма согласия как основа стратегии будущего [Электронный ресурс] // Горизонты гуманитарного знания. 2017, № 3. URL: http://journals.mosgu.ru/ggz/article/view/516 (дата обращения: АА.мм.гггг.). DOI: 10.17805/ ggz.2017.3.6 